\title{
Shake Table Testing of Seismic Soil-Foundation-Structure-Interaction
}

\author{
Robb E. S. Moss , Steven Kuo and Victor Crosariol
}

\begin{abstract}
This research involves shake table testing of $1 \mathrm{~g}$ scale models that mimic the coupled seismic response of a structure on a shallow mat foundation and the foundation soil (termed soil-foundation-structure-interaction or SFSI). In previous research, SFSI effects have been quantified through analytical models, numerical analyses, and limited field data. This research is working towards increasing the amount of empirical data through scale model shake table testing. A suite of earthquake times histories are considered in evaluating a $10^{\text {th }}$ scale soil-structure model using a flexible wall barrel on a 1-D shake table. San Francisco Young Bay Mud (YBM) is used as the prototype soil and a 3-5 story narrow building the prototype structure. Foundation embedment depth, fundamental mode of the structure, dynamic soil strength, and seismic loading function are varied to generate a large database of SFSI results under controlled conditions. The structural response is compared to free-field response to determine the magnitude of the SFSI. A presentation of the full test results is anticipated at the time of the conference.
\end{abstract}

\section{INTRODUCTION}

In recent studies, the effects of the SFSI have been found to alter the seismic response of shallow foundation buildings (Stewart et al., 1999b,c). There are many issues associated with the effects of the soil on the structural elements during seismic loading that could be better explored. This research investigates the effects of foundation embedment depth in relation to the structural response acquired through empirical modeling and shake table testing.

The two mechanisms of physical interaction between the structure, soil, and foundation are; 1) inertial interaction, and 2) kinematic interaction. The inertia developed in the structure due to its own vibration induces base shear and moment, which results in the displacement of the foundation relative to the free field. The kinematic interaction from the stiff foundation induces the foundation motion to deviate from the free field response. In this research, both inertial interaction and kinematic interaction of a shallow foundation on soft soil will be captured. A system commonly employed in simple analysis of inertial interaction, illustrated in Fig. 1, 
consists of a single-degree-of-freedom structure of height $h$ on a foundation with frequency dependent and complex valued translation and rotational springs $\mathrm{k}_{\mathrm{u}}$ and $\mathrm{k}_{\Theta}$. The mass $m$, stiffness $k$, and damping $c$, along with the impedance function are shown.

Illustrations of the kinematic and inertial interactions of soil are shown in Fig. 2. The free field and foundation level peak horizontal accelerations and the 5\% damped spectral accelerations are compared. The curves, based on analytical results and empirical field data, show a general agreement between the free field and the surface foundation. However, there is a slight deamplification in the response of the foundation as embedment increases. This shake table research plans to provide empirical data to better define these trends in a controlled lab environment.

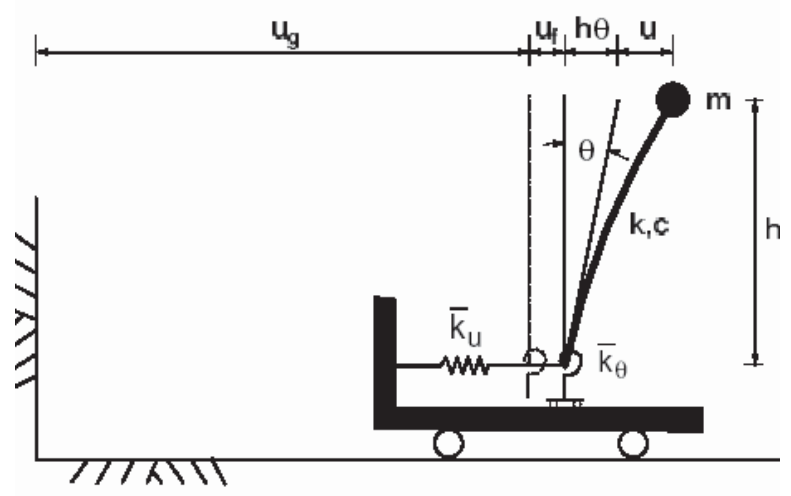

Figure 1. Simplified Model for Analysis for Inertial Interaction (from Stewart et al., 1999b)
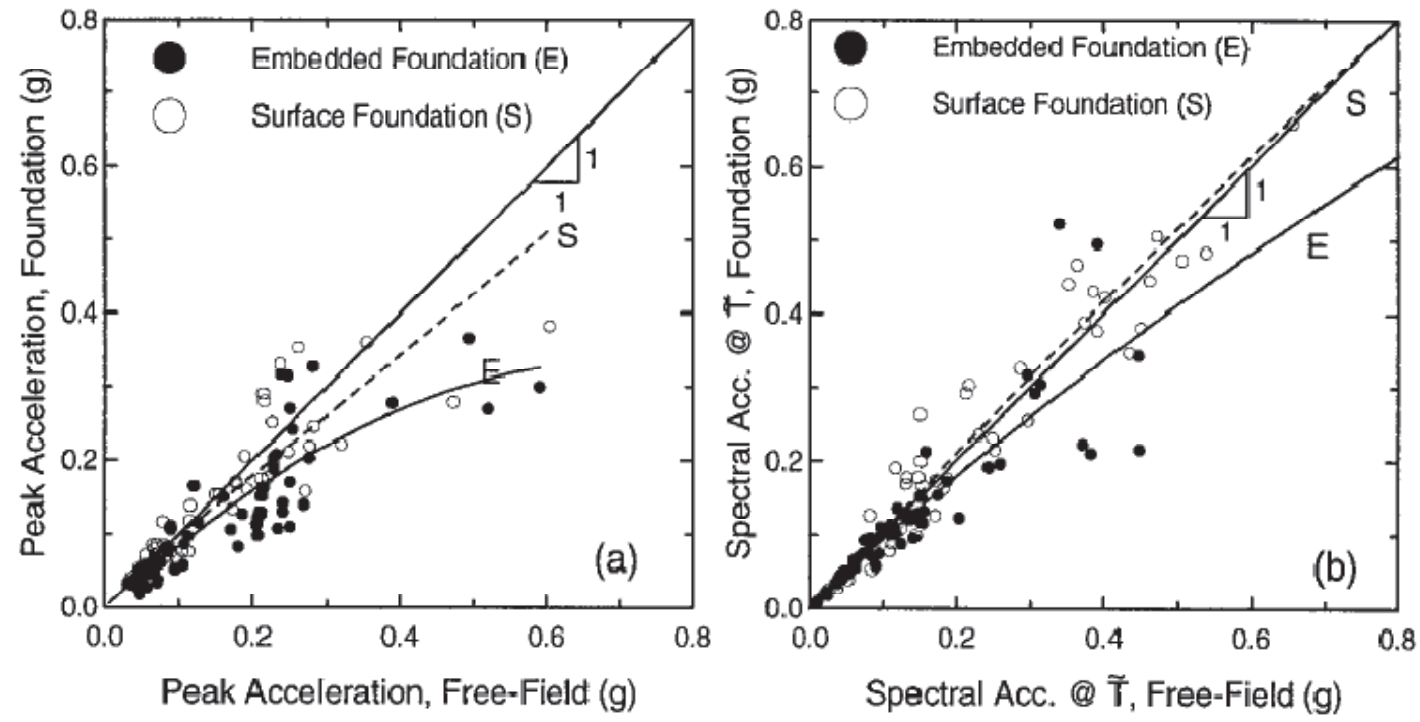

Figure 2. Comparison of free-field and foundation level structure motions: (a) peak acceleration data; (b) $5 \%$ damped spectral acceleration comparison (from Stewart et al., 1999c) 


\section{TESTING PLATFORM}

In order to produce valid empirical scale model tests on the shake table, similitude analysis of the important variables that affect the overall performance must be evaluated. Factors such as the dynamic soil strength, structural period, dynamic structural response, and time step of the ground motion must be scaled according to similitude laws as was described for this type of dynamic testing by Meymand (1998). There are two different shake tables that used in this research. Fig. 3 shows the smaller 1-D shake table in the Advance Soils Lab at Cal Poly which is used to confirm the natural period and dynamic response of the scale model structure. Fig. 4 illustrates the larger 1-D shake table that is located in the Parsons Earthquake Lab at Cal Poly. The bulk of the SSI testing will be done on the larger shake table.

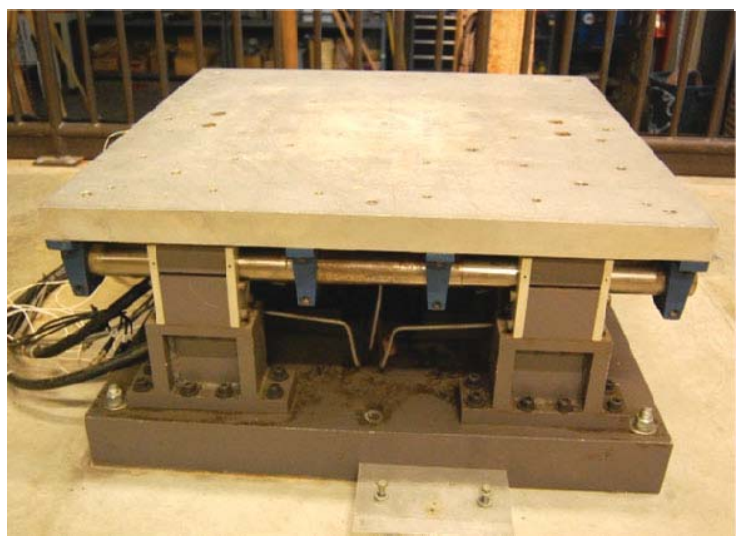

Figure 3. Small shake table at Cal Poly's Advanced Soils Lab used in testing dynamic behavior of the scale model structure.

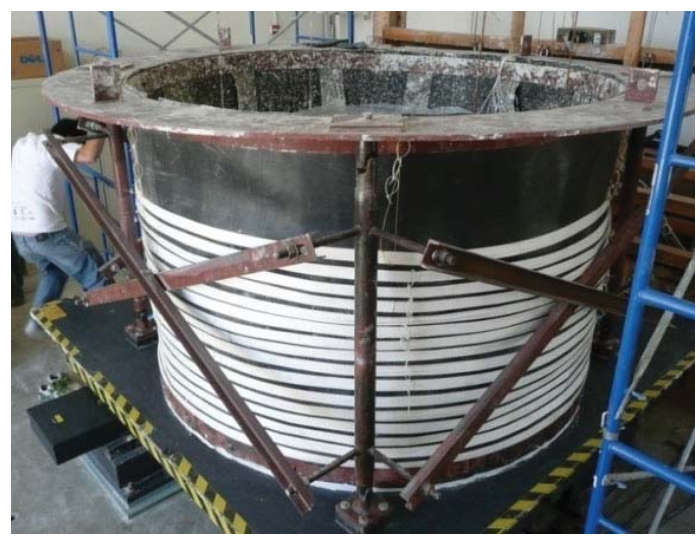

Figure 4. The testing platform shown consists of the shake table and flexible wall barrel at Cal Poly's Parsons Earthquake Lab.

The main testing equipment is a flexible wall barrel that mimics free field site response under seismic loading on the shake table. The flexible wall barrel has been validated through table testing and 1-D equivalent linear numerical analysis in a recently completed research project (Crosariol, 2010; Moss et al., 2010). Figures 5 and 6 demonstrate the dynamic performance of the flexible wall barrel versus the other testing platforms. The prototype soil column has a seismic response that is most similar to the result from the flexible wall barrel.

The flexible wall barrel is filled with a mixture of model soil using an industrial scale mixer shown in Figure 7. The prototype soil in this research is the San Francisco young bay mud (YBM). The similitude scaling parameter $(\lambda)$ is at $10^{\text {th }}$ scale for this series of test. The dynamic strength of the prototype is the primary soil variable scaled for this test. A mix of kaolinite, bentonite, fly ash, and water are used in specific volumes to achieve the proper scaled strength to hit the target prototype strength. The mix has an average $110 \%$ water content, and the target undrained strength is $4 \mathrm{kPa}$ which gives a typical dynamic undrained strength ratio $\left(\mathrm{s}_{\mathrm{u}} / \sigma_{\mathrm{v}}{ }^{\prime}\right)$ for YBM. This mix of the soil was developed and tested and validated through the previous research by Meymand (1998) and Crosariol (2010). 


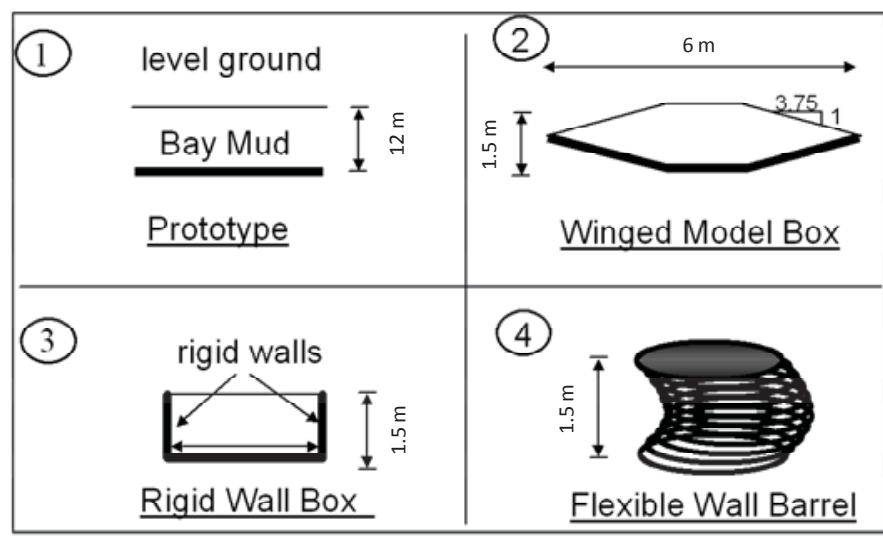

Figure 5. Different model soil containers for SSI shake table testing (after Meymand, 1998).

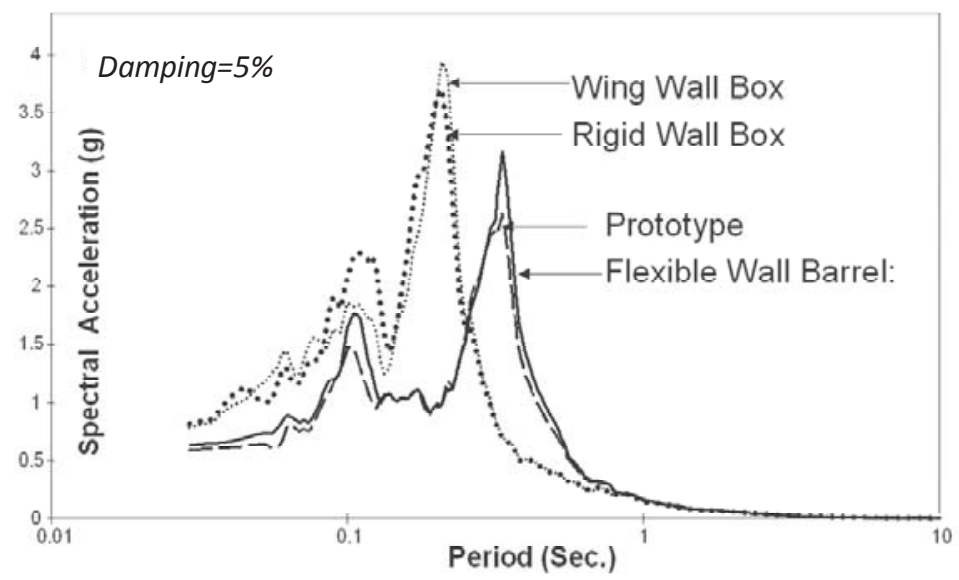

Figure 6. Dynamic analysis of different model soil containers. showing that the flexible wall barrel provides the most realistic response when compared to prototype field conditions (after Meymand, 1998).

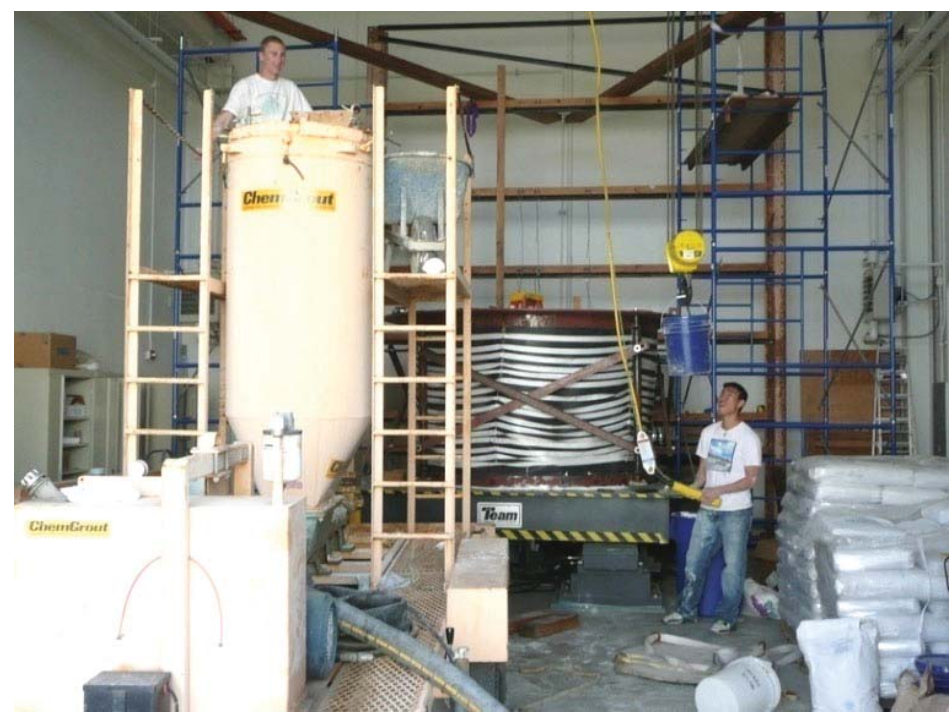

Figure 7. The flexible wall barrel is composed of the four corner posts with universal joints at the top and bottom, the top and bottom rings, and the barrel wall. The wall is composed of a 6.4 mm thick rubber membrane which is confined by $45 \mathrm{~mm}$ wide Kevlar straps spaced on center every $60 \mathrm{~mm}$. The (yellow) mixer on the left is used to mix the large volumes of model soil (composed of kaolinite, bentonite, fly ash, and water) for filling the barrel. 
The 1D shake table in the Parsons Earthquake Lab at Cal Poly has a $4500 \mathrm{~kg}$ payload capacity. With the maximum payload the table can accelerate up to $1 \mathrm{~g}$, has a maximum velocity of $97 \mathrm{~cm} / \mathrm{sec}$, a maximum peak to peak displacement of $25 \mathrm{~cm}$, and operates in the frequency range of 0.1 to $50 \mathrm{~Hz}$. A full flexible wall barrel and accompanying equipment are estimated to weigh on the order of $3500 \mathrm{~kg}$.

\section{TESTING}

A single degree of freedom (SDOF) structural model was chosen for the current SSI test. The structure aims to mimic the seismic response of a narrow 3 to 5story building. Figure 8 shows the complete model with the "basement" walls constructed out of aluminum frame and acrylic boards. The threaded steel rod allows for the height and the mass to be adjusted to vary the period of the structure. The steel plate serves as a rigid mat foundation.

The testing of this project is divided into two phases. During the first phase, the model is fixed to the small shake table to capture the natural period and response of the structure to serve as a baseline response. In phase two on the large shake table, the same model is embedded in the soil at various depths, and the free field data are collected simultaneously with the structure response for direct comparison. All three data sets are analyzed to determine the relationship of embedment depth to the seismic response of the structure. The empirical results will be compared to those of the numerical equivalent-linear soil-foundation-structure interaction code FLUSH (Lysmer et al., 1975) to explore broader conditions and make recommendations for predictive numerical modeling of similar prototype situations.

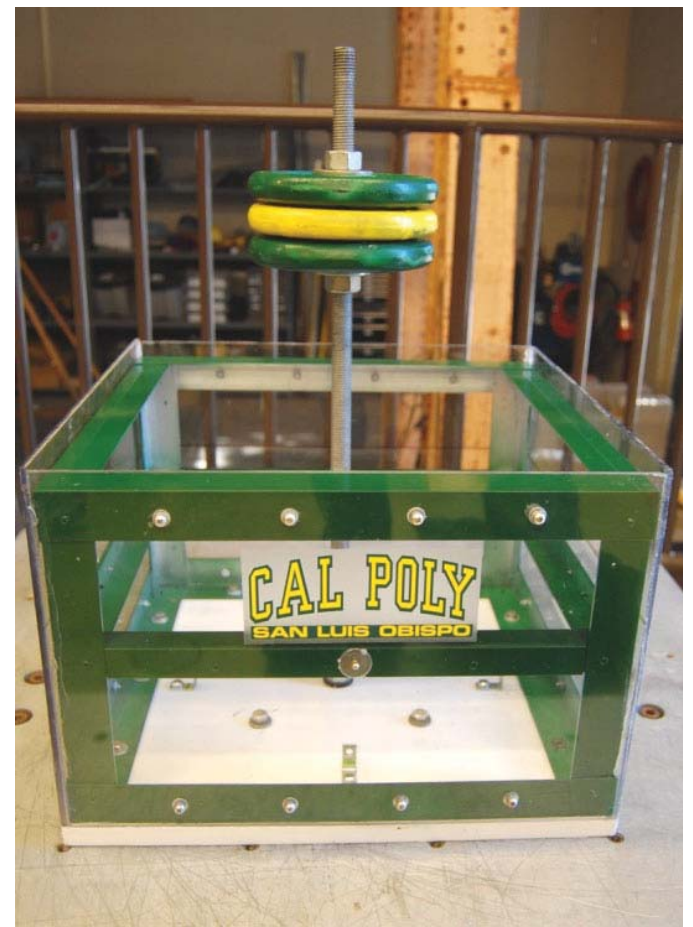

Figure 8. During phase one, the natural frequency of various SDOF setups are determined using the small shake table. The foundation is $46 \mathrm{~cm}$ by $46 \mathrm{~cm}$, and the "basement" walls are $32 \mathrm{~cm}$ tall. 
Unlike phase one which records the natural periods of the model with different damp mass heights from sine wave sweep, phase two testing uses recorded earthquake time histories for the loading. The free field data and the structural response are collected simultaneous by using two arrays of accelerometers to capture the SSI effect. The free field data provides a baseline for evaluating the effect of the soil on the structure.

Figures 9 and 10 show the plan and elevation views of the instrument layout and model placement in the barrel. The accelerometers are placed in two vertical arrays $0.5 \mathrm{~m}$ away from center of the barrel perpendicularly to the shaking direction. The model is located on center above one of the arrays, while the other array acts as the free field soil column. The boundary effects of the wall have been found to be minimal within $0.76 \mathrm{~m}$ radius of the barrel (Crosariol, 2010). Pull out T-bar tests measure the undrained shear strength from the bottom up, which is mated to top down shear wave velocity measurements from hammer blow tests.

The embedment depth of the model is to be varied at the depth increments of $0 \mathrm{~cm}, 15$, and $30 \mathrm{~cm}$. A suite of recorded ground motions have been selected specifically for this project to cover a broad seismic demand range. In accordance with similitude analysis, the time parameters of the ground motions are scaled at $\lambda^{0.5}$ to provide accurate dynamic response which results in a time compression by $\Delta \mathrm{t} / \lambda^{0.5}$.

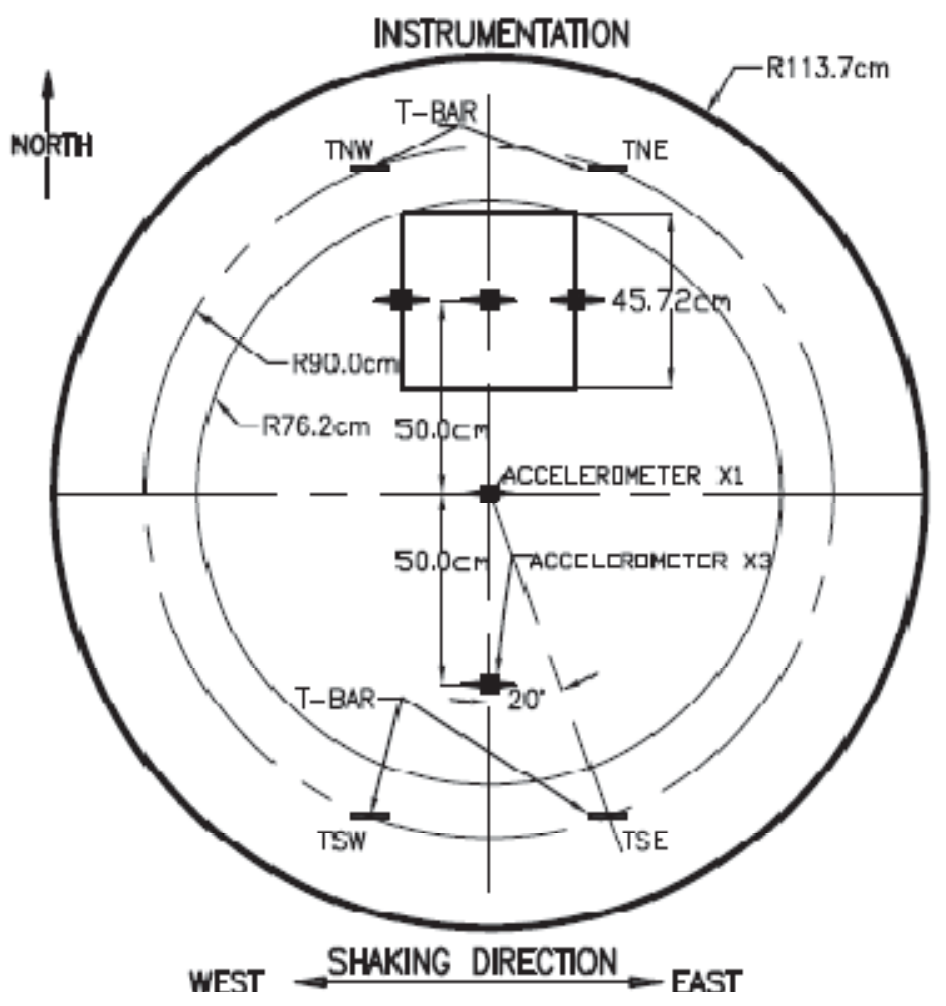

Figure 9. Plan view of the flexible wall barrel showing the accelerometer array layout, T-bar locations, and dimensions. 


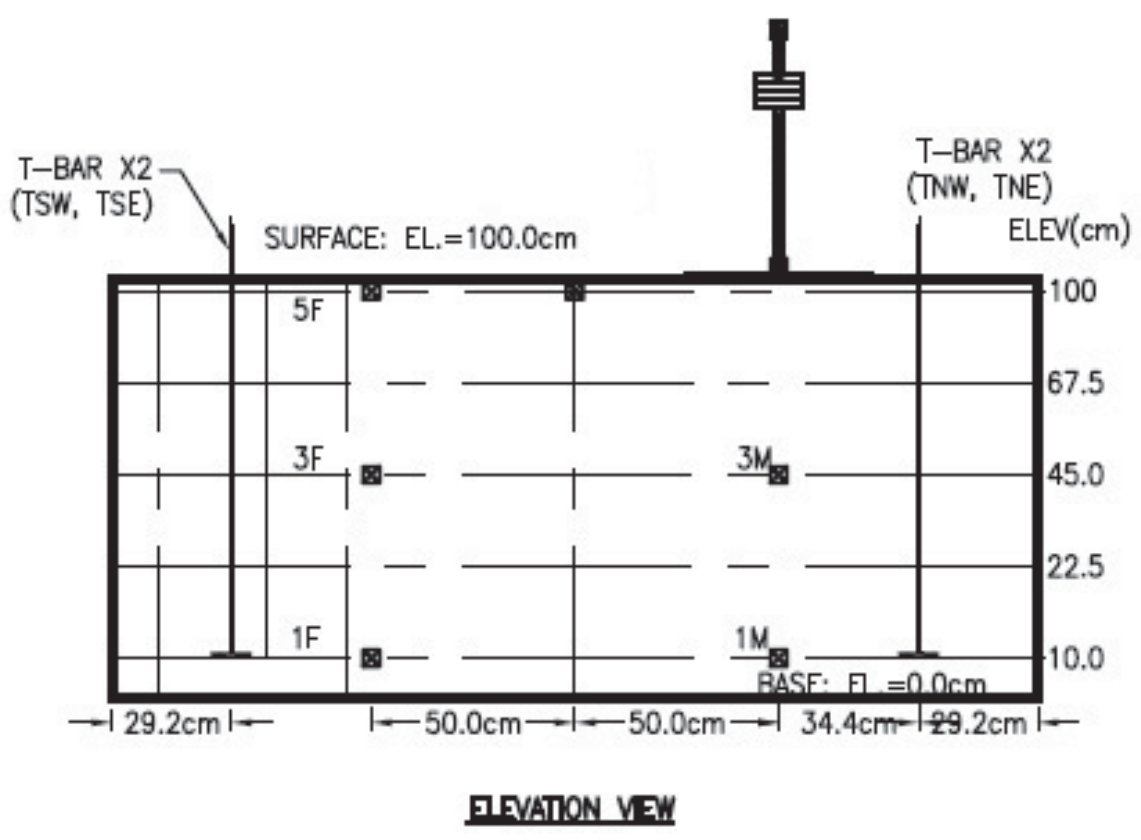

Figure 10. Elevation view of the flexible wall barrel showing the place of the two accelerometer arrays, T-bar depth and dimensions. Shaking direction is in and out of the page (North-South).

\section{PREVIOUS RESULTS}

The SDOF model testing results will be compared to the free-field results to observe the trend of the interaction between the soil and the structure. The primary goal is to populate Figure 2 with a series of controlled lab data sets that we anticipate will better match the analytical results when compared to the field data. Previous SSI research using a similar soil profile and testing set up was done on the Cal Poly shake table using a scale model subway tunnel cross-section embedded in the soil to measure the racking deformations of the ceiling with respective to the floor under seismic loading (Crosariol, 2010). In Figure 11, the average peak acceleration from the buried scale model are plotted against the data extracted from Figure 2. The results from the previous underground structure show a favorable trend that validates the thesis of the proposed research. The underground structure has lower peak accelerations compare to the free-field results as a result of inertial and kinematic interaction between the structure and the soil. 


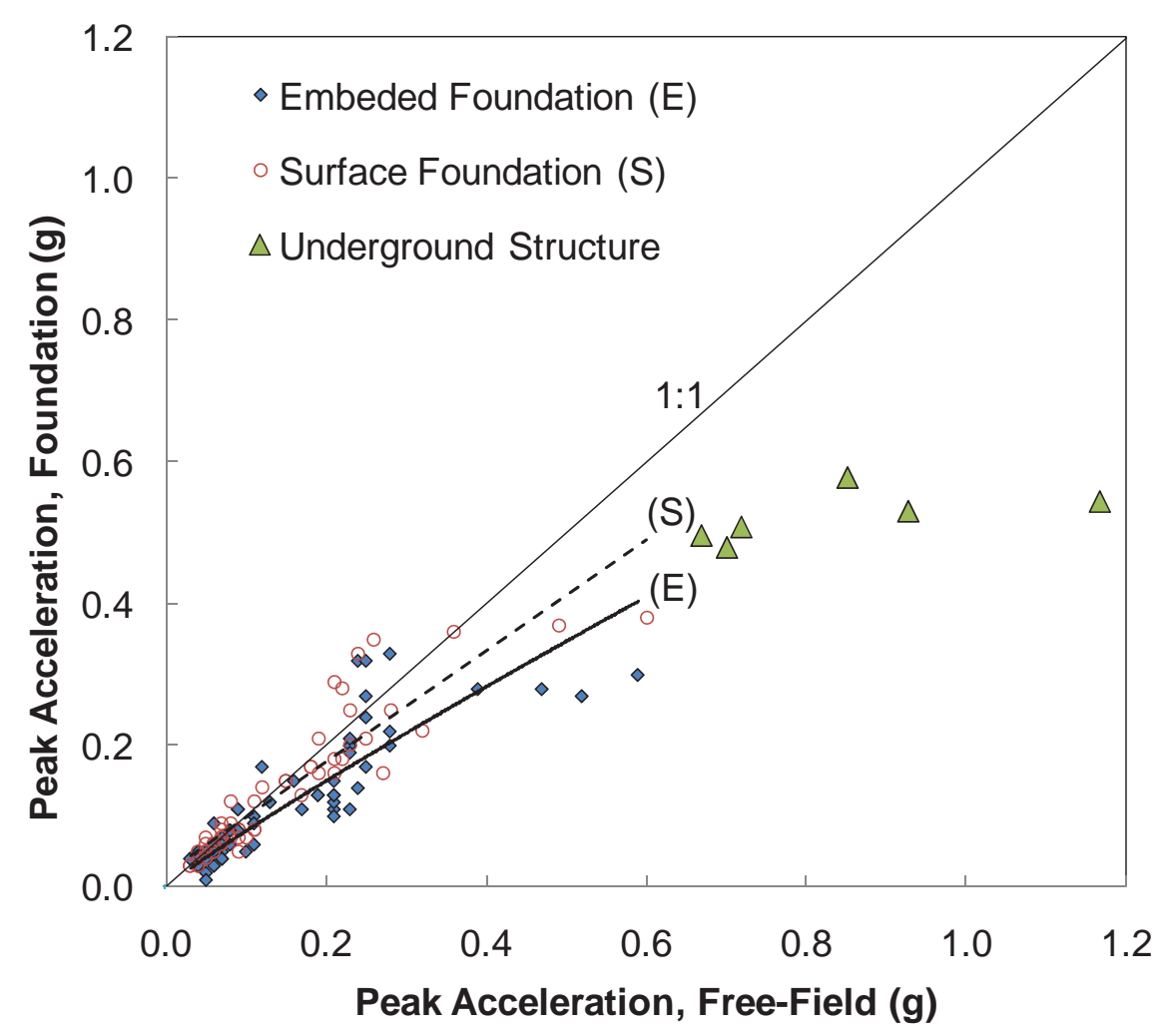

Figure 11. Comparison of the free-field and the foundation level peak acceleration data extracted from Stewart et al. (1999a) compared with data from recent scale model underground SSI testing by Crosariol (2010).

\section{SUMMARY}

This manuscript presents research examining the effects of seismicfoundation-structure interaction of a SDOF mat foundation on soft clay soil. The goal of the research is to provide a controlled lab approach for gathering empirical data on foundation deamplification for various embedment depths. Shake table response of free field data is collected simultaneously with embedded scale model response for direct analysis to determine the relationship. A $10^{\text {th }}$ scale model was developed for this testing program. The platform consists of a flexible wall barrel, scale model soil, and other corresponding testing equipment. A small shake table is used during the first phase to analyze the model structure, and a large shake table during the second phase testing for full soil-structure-interaction analysis. The first phase of the testing is currently underway, with the second phase results anticipated by the time of the conference presentation. The empirical results will be compared to those of the numerical equivalent linear soil-foundation-structure interaction code (FLUSH) to explore broader conditions and make recommendations for predictive numerical modeling of similar prototype situations. Previous research using the same testing platform but investigating underground SSI behavior shows the promise of this research in providing empirical data where little currently exists that is gathered in a controlled laboratory setting. 


\section{REFERENCES}

Crosariol, V. (2010) "Scaled 1g Testing of Soil-Structure-Interaction Models" Masters Thesis, Cal Poly San Luis Obispo.

Idriss, I.M., and Sun, J.I. (1992) "User's Manual for SHAKE91: A computer program for conducting equivalent linear seismic response analysis of horizontally layered soil deposits."

Lysmer, J., Udaka, T., Tsai, C-F., Seed, H.B. (1975) "FLUSH: a computer program for approximate 3-D analysis of soil-structure interaction problems." UCB/EERC-75/30, Earthquake Engineering Research Center, University of California, Berkeley, 1975-11, 139 pages (555.6/L92/1975)

Meymand, P. J. (1998). "Shaking Table Scale Model Tests of Nonlinear Soil-PileSuperstructure Interaction in Soft Clay," Ph.D. Dissertation, Civil and Environmental Engineering Department, U.C. Berkeley.

Moss, R. E. S., Crosariol, V., and Kuo, S. (2010). "Shake table testing to quantify seismic soil-structure-interaction of underground structures." 5th International Conference on Recent Advances in Geotechnical Earthquake Engineering and Soil Dynamics, San Diego, May 24-29.

Stewart, J. P., Seed, H. B., and Fenves, G. L. (1999a) "Empirical Evaluation of Inertial Soil-Structure Interaction Effects." PEER-98/07, Pacific Earthquake Engineering Research Center, University of California, Berkeley.

Stewart, J. P., Seed, H. B., and Fenves, G. L. (1999b). "Seismic Soil-Structure Interaction in Buildings. I: Analytical Methods." Journal of Geotechnical and Geoenvironmental Engineering, 121(1).

Stewart, J. P., Seed, H. B., and Fenves, G. L. (1999c). "Seismic Soil-Structure Interaction in Buildings. II: Empirical Findings." Journal of Geotechnical and Geoenvironmental Engineering, 121(1). 